\title{
Studi Perbandingan Pengajaran Reaksi Reduksi Oksidasi Antara Cara Perubahan Bilangan Oksidasi dengan Cara Setengah Reaksi terhadap Hasil Belajar Siswa Kelas XII IPA 1 dan XII IPA 2
}

\author{
Fauziah \\ SMA Negeri 13 Kota Jambi \\ Correspondence email: Fauziahde56@gmail.com
}

\begin{abstract}
Abstrak. Reaksi reduksi Oksidasi (redoks) adalah salah satu reaksi disetarakan, artinya sukar untuk mencari koefisien reaksi yang cocok. Jalan yang lebih mudah dan logis dengan mengingat bahwa reaksi redusi dan reaksi oksidasi berlangsung secara simultan. Reaksi redoks dapat disetarakan dengan dua cara, yaitu dengan cara perubahan bilangan oksidasi dan cara setengah reaksi (ion elektron). Kemampuan siswa dalam menyelesaikan persamaan reaksi redoks dapat dilihat dari hasil belajar yang dicapai. Penelitian ini bertujuan untuk mengetahui apakah ada perbedan pengajaran reaksi reduksi oksidasi antara cara perubahan bilangan oksidasi dengan cara setengah reaksi dalam penyetaraan persamaan reaksi redoks terhadap hasil belajar siswa. Anggota populasi adalah siswa kelas XII MIPA 1 dan kelas XII MIPA 2 SMAS Pertiwi yang mempelajari reaksi reduksi oksidasi. Sampel dalam penelitian ini adalah siswa kelas XII MIPA 1 dan kelas XII MIPA 2 SMAS Pertiwi. Alat ukur yang digunakan adalah tes yang memenuhi standar pmbakuan soal. Uji normalitas dan uji homogenitas sampel dilakukan sebelum uji hipotesis dilaksanakan. Nilai rata-rata hasil belajar siswa dengan cara perubahan bilangan oksidasi dan cara setengah reaksi yaitu sebesar 11,75 dan 10,8. Harga t hitung sama dengan 1,81 sedangkan harga t tabel sama dengan 2,00 pada taraf signifikansi 0,05. Dari data di atas dapat disimpulkan bahwa tidak ada perbedaan hasil belajar siswa antara cara perubahan bilangan oksidasi dan cara setengah reaksi dalam menyetarakan persamaan reaksi redoks untuk aspek aplikasi.
\end{abstract}

Kata kunci: reaksi reduksi oksidasi; bilangan oksidasi; hasil belajar

Abstract._Oxidation-Reduction Reactions (Redox) are one of the hardest reactions to equalize, this means that it is hard to determine the suitable Reaction Coefficient. An easier and more logical train of thought is to remember that a Reduction and an Oxidation reaction happens simultaneously. A Redox Reaction has two methods in order to equalize, that which is by using the "Change in Oxidation Number" method or the "Half-Reaction (Ion-Electron)" method. The students' skills in completing a Redox Reaction can be observed in the grades that they have achieved. This observation is intended to find out if there is a difference in students' grades if you were to teach them about the equalization of Redox Reactions using either of these two methods (the "Change in Oxidation Number" method and the "Half-Reaction" method). The population in this observation consists of the students of Class XII IPA 1 and Class XII IPA 2 of SMAS PERTIWI Jambi that are studying Oxidation-Reduction Reactions. Sample members consist of the students of Class XII IPA 1 and the students of Class XII IPA 3 of SMAS Pertiwi Jambi. The measuring instrument used is a test that has fulfilled standards. Normality tests and Homogeneity tests of the sample in question has been done before the Hypothetical test was implemented. The average grades of students using the "Change in Oxidation Number" method and the "Half-Reaction" method is 11.75 and 10.8 respectively. The T-value of calculations is approximately 1.81 while the T-value of tables is approximately 2.00. With the Level of Significance being 0.05. From the data provided above, it can be concluded that there is no difference in student grades whether the "Change in Oxidation Numbers" method or the "Half-Reaction" method is used to equalize Redox Reactions in applicative aspects.

Keywords: oxidation reduction reaction; oxidation number; learning outcomes

\section{PENDAHULUAN}

Pendidikan adalah serangkaian kegiatan komunikasi yang bertujuan antara manusia dewasa dengan anak didik secara tatap muka dengan menggunakan media dalam rangka memberikan bantuan terhadap perkembangan anak didik seutuhnya, dalam arti agar dapat mengembangkan potensinya semaksimal mungkin supaya menjadi manusia dewasa yang bertanggung jawab. Potensi yang dimaksud adalah potensi fisik, sosial, moral, pengetahuan dan keterampilan (Idris, 1987).

Jika ditelaah definisi pendidikan di atas, pada prinsipnya dapat diperoleh gambaran bahwa:
1. Pendidikan merupakan suatu proses yang melibatkan berbagai unsur mulai dari anak didik sebagai input material untuk mencapai tujuan pendidikan.

2. Subyeknya adalah anak didik yang secara kodrati harus dipandang sebagai makhluk individu, makhluk sosial dan makhluk Tuhan.

3. Adanya tujuan yaitu agar semua potensinya berkembang atau terbentuknya perubahan tingkah laku sehingga anak didik menjadi manusia dewasa yang bertanggung jawab, baik bagi dirinya maupun bagi manusia.

Belajar merupakan aktivitas dan kepentingan setiap individu karena semua pengetahuan, keterampilan, 
nilai dan tingkah laku individu terbentuk dan disesuaikan dengan belajar yang dilakukannya (Abdulhak, 1986). Sedangkan gaya mengajar menempatkan subyek didik sebagai titik pusat kegiatan belajar mengajar, merupakan keputusan yang tepat, yang dapat menghasilkan suatu proses belajar mengajar yang efektif dan efisien.

Mengajar bukan hanya mentransfer sesuatu melainkan suatu usaha membina, membantu, memotivasi dan memberikan fasilitas siswa dalam mencapai keberhasilan (Nasution, 1987). Proses belajar mengajar selalu melibatkan guru dan murid sebagai penerima informasi, perlu adanya cara tertentu agar informasi yang diberikan oleh guru dapat diterima secara efektif sesuai dengan tujuan yang diharapkan. Cara yang dimaksud adalah penggunaan cara pengajaran dalam menyampaikan suatu materi pelajaran. Guru yang baik bukan mengajar dengan satu cara saja. Ia harus memakai cara mengajar yang paling cocok untuk mencapai tujuan pengajaran yang tertentu (Nasution, 1987).

Pengajaran reaksi redoks adalah salah satu pokok bahasan dalam ilmu kimia yang diberikan pada sistem Sekolah Menengah Atas (SMA) atau yang sederajat, jurusan MIPA dan sekolah-sekolah kejuruan, yang merupakan bagian dari Ilmu Pengetahuan Alam (IPA).

Reaksi reduksi oksidasi merupakan suatu kelompok jenis reaksi kimia yang penting. Reaksi reduksi oksidasi sudah lama dikenal namun konsep dan pengertiannya berkembang sesuai dengan perkembangan ilmu kimia. Konsep kimia yang dikemukakan bahwa peristiwa reduksi oksidasi ialah terjadinya peristiwa kimia yang ada hubungannya dengan oksigen. Konsep ini kemudian berkembang bahwa peristiwa reduksi oksidasi berhubungan dengan perpindahan elektron. Konsep bilangan oksidasi dan reduksi dihubungkan dengan kemudahan penyetaraan reaksi reduksi oksidasi dan penentuan koefisien-koefisien reaksi reduksi oksidasi. Dalam hal ini, reaksi reduksi oksidasi dianggap sebagai penggabungan dua sistem atau setengah reaksi. Cara ini dinamakan metode ion elektron atau setengah reaksi (Polling dan Tjokrodanoerdjo, 1989).

Penyetaraan persamaan reaksi reduksi oksidasi (redoks) dapat disetarakan dengan dua cara, yaitu:

1. Cara perubahan bilangan oksidasi

2. Cara setengah reaksi

Semua reaksi redoks dapat diberimbangkan baik dengan cara perubahan bilangan oksidasi ataupun cara setengah reduksi (Keenan, Kleinfelter dan Wood, 1986). Urutan tahap-tahap penyetaraan persamaan reaksi redoks dengan cara perubahan bilangan oksidasi berbeda dengan urutan tahap-tahap penyetaraan reaksi redoks dengan cara setengah reaksi tapi hasil persamaan reaksi redoks adalah sama.

Lazimnya, setiap pokok bahasan atau sub pokok bahasan pada akhir pengajaran akan diberikan evaluasi hasil belajar yang berfungsi untuk mengetahui seberapa jauh hasil yang telah dicapai dalam proses pendidikan yang telah dilaksanakan. Apakah hasil yang dicapai sudah sesuai dengan yang diharapkan atau belum (Nurkancana dan Sumartana, 1986). Dari uraian di atas, timbul suatu permasalahan, dengan urutan tahap-tahap penyetaraan persamaan reaksi redoks antara cara perubahan bilangan oksidasi dengan cara setengah reaksi yang berbeda, tapi hasil akhir persamaan reaksi redoks untuk kedua cara tersebut adalah sama. Apakah hasil belajar siswa yang diberikan pengajaran cara perubahan bilangan oksidasi akan sama dengan hasil belajar siswa yang diberikan pengajaran cara setengah reaksi?

\section{Tinjauan Pustaka}

Pendidikan nasional merupakan suatu sistem. Yang dimaksud sistem di sini adalah sekelompok komponen yang berkaitan dengan yang lainnya, sehingga keseluruhannya mampu melaksanakan fungsifungsi tertentu. Kerja atau operasi suatu sistem dibagi dalam tiga tahap, (Ronowisroyo, 1980):

1. Input atau masukan yaitu sesuatu yang dimasukkan ke dalam sistem.

2. Proses, yaitu hal-hal yang berlangsung dalam sistem.

3. Output atau keluaran, yaitu hasil-hasil yang keluar dari sistem.

Ketiga tahap di atas saling berinteraksi satu dengan yang lainnya, sehingga mampu melaksanakan fungsi-fungsi tertentu dalam rangka mencapai hasil yang diinginkan.

Belajar merupakan salah satu kebutuhan hidup manusia yang sangat vital dalam usahanya untuk mempertahankan hidup dan mengembangkan dirinya dalam kehidupan bermasyarakat dan bernegara.

Menurut Nasution (1987) dalam proses belajar dapat dibedakan tiga fase atau periode, yakni: (1) Informasi, (2) Transformasi, (3) Evaluasi.

Menurut Mappa, Achsin dan La Sulo (1984) mengajar adalah kegiatan yang dilakukan secara sadar oleh seorang atau tim untuk membantu seseorang atau sekelompok orang yang melakukan kegiatan belajar, sehingga proses belajar mengajar berlangsung secara efektif dan efisien.

\section{METODE}

\section{Populasi Penelitian}

Populasi penelitian adalah siswa kelas XII SMAS Pertiwi Kota Jambi yang mempelajari pokok bahasan reaksi Reduksi Oksidasi.

\section{Sampel Penelitian}

Sampel penelitian adalah siswa kelas XII MIPA 1 dan kelas XII MIPA2 SMAS Pertiwi Kota Jambi yang bersifat paralel. Penempatan siswa pada program MIPA di antaranya adalah berdasarkan kepada prestasi belajar, 
Fauziah, Studi Perbandingan Pengajaran Reaksi Reduksi Oksidasi Antara Cara Perubahan Bilangan Oksidasi dengan Cara Setengah Reaksi terhadap Hasil Belajar Siswa Kelas XII IPA 1 dan XII IPA 2

bakat dan minat siswa. Oleh karena itu, kelas XII MIPA 1 dan kelas XII MIPA 2 dijadikan sampel penelitian dengan asumsi bahwa latar belakang pola berpikir siswa adalah cenderung sama.

\section{Instrumen Penelitian}

Pengukuran hasil belajar siswa biasanya digunakan instrumen hasil belajar yang dipilih dari soalsoal yang terdapat dalam sumber bacaan. Instrumen ini diuji coba pada siswa kelas XII MIPA1 SMASPertiwi Kota Jambi pada tanggal 1 September 2015. Pembakuan soal instrumen dilakukan analisis validitas, reliabilitas, derajat kesukaran dan daya beda. Baik buruknya suatu tes atau suatu alat evaluasi dapat ditinjau dari segi (1) validitas, (2) reliabilitas, (3) daya beda dan (4) derajat kesukaran (Nurkancana dan Sumartana, 1986).

\section{Validitas}

Validitas butir soal adalah tingkat ketepatan dari butir soal tersebut dalam mengukur apa yang harus diukur (Subino, 1987). Sebuah item memiliki validitas yang tinggi jika skor pada item mempunyai kesejajaran dengan skor total. Kesejajaran ini dapat diartikan dengan korelasi, sehingga untuk mengetahui validitas item digunakan rumus korelasi biserial (Arikunto, 1990) sebagai berikut:

$$
\gamma p b i=\frac{M_{p}-M_{t}}{S_{t}} \cdot \sqrt{\frac{p}{q}}
$$

Keterangan:

$$
\begin{aligned}
& \gamma p b i=\text { Koefisien korelasi biserial } \\
& M_{p} \quad=\text { Rerata skor dari subyek yang menjawab betul } \\
& \text { bagi item yang dicari validitasnya } \\
& M_{t} \quad=\text { Rerata skor total } \\
& S_{t} \quad=\text { Standar deviasi dari skor total } \\
& p \quad=\text { Proporsi siswa yang menjawab benar } \\
& \left(p=\frac{\text { banyaknya siswa yang menjawab benar }}{\text { jumlah seluruh siswa }}\right)
\end{aligned}
$$

$q \quad=$ Proporsi siswa yang menjawab salah

$$
(q=1-p)
$$

\section{Reliabilitas}

Suatu tes dapa dikatakan sebagai suatu tes yang reliabel, apabila tes tersebut menunjukkan hasil-hasil yang mantap, bila diuji coba beberapa kali. Tingkat reliabilitas dinyatakan dengan koefisien reliabilitas. Koefisien reliabilitas dari suatu instrumen yang terpilih dapat dihitung dengan menggunakan rumus KuderRichardson-20, untuk mengatasi kesulitan metode dua belah yang banyaknya item harus genap agar dapat dibelah (Arikunto, S, 1990). Rumus Kuder-Richardson20 adalah sebagai berikut: $r_{11}=\left(\frac{n}{n-1}\right) \cdot\left(\frac{s^{2}-\sum p q}{s^{2}}\right)$

Keterangan:

$r_{11}=$ Reliabilitas tes secara keseluruhan

$p \quad=$ Proporsi subyek yang menjawab item dengan benar

$q \quad=$ Proporsi subyek yang menjawab item dengan salah

$$
\begin{aligned}
\sum_{n} p q & (q=1-p) \\
= & \text { Jumlah hasil perkalian } p \\
S & =\text { Banyaknya item } \\
= & \text { Standar deviasi dari tes }
\end{aligned}
$$

\section{HASIL DAN PEMBAHASAN}

Penelitian pendahuluan dilaksanakan di kelas XII IPA1 dan kelas XII IPA 2 SMAS Pertiwi Kota Jambi. Jumlah soal yang diberikan kepada siswa kelas XII MIPA1 dan kelas XII IPA 2 SMAS Pertiwi Kota Jambi sebanyak lima soal dalam bentuk esai. Masing-masing soal dinilai berdasarkan langkah-langkah penyetaraan persamaan reaksi reduksi oksidasi dengan cara perubahan bilangan oksidasi dan dengan cara setengah reaksi.

Langkah-langkah yang dinilai untuk penyetaraan persamaan reaksi reduksi oksidasi dengan cara perubahan bilangan oksidasi adalah:

1. Penentuan reaksi oksidasi dan reaksi reduksi

2. Perubahan bilangan oksidasi unsur dalam senyawa

3. Jumlah $\mathrm{H}^{+}$atau jumlah $\mathrm{OH}^{-}$

4. Jumlah $\mathrm{H}_{2} \mathrm{O}$

Langkah-langkah penyetaraan reaksi reduksi oksidasi dengan cara setengah reaksi yang dinilai adalah:

1. Penentuan reaksi oksidasi dan rekasi reduksi

2. Jumlah $\mathrm{H}^{+}$atau jumlah $\mathrm{OH}^{-}$

3. Jumlah $\mathrm{H}_{2} \mathrm{O}$

4. Jumlah elektron yang diterima dan yang dikeluarkan

Hasil analisis uji validitas, reliabilitas, derajat kesukaran dan daya beda, ternyata langkah-langkah penyetaraan persamaan reaksi reduksi oksidasi dengan cara perubahan bilangan oksidasi dan dengan cara setengah reaksi yang memenuhi standar adalah:

1. Cara perubahan bilangan oksidasi:

a. Penentuan bilangan oksidasi unsur dalam senyawa

b. Jumlah $\mathrm{H}^{+}$atau jumlah $\mathrm{OH}^{-}$

c. Jumlah $\mathrm{H}_{2} \mathrm{O}$

2. Cara setengah reaksi:
a. Jumlah $\mathrm{H}^{+}$atau jumlah $\mathrm{OH}^{-}$
b. Jumlah $\mathrm{H}_{2} \mathrm{O}$
c. Jumlah elektron yang diterima dan yang dikeluarkan 
Fauziah, Studi Perbandingan Pengajaran Reaksi Reduksi Oksidasi Antara Cara Perubahan Bilangan Oksidasi dengan Cara Setengah Reaksi terhadap Hasil Belajar Siswa Kelas XII IPA 1 dan XII IPA 2

\section{Validitas}

Hasil analisis validitas untuk cara perubahan bilangan oksidasi dalam menyetarakan reaksi reduksi oksidasi berkisar antara 0,000 sampai 0,924 validitas rata-rata 0,6146 . Sedangkan untuk cara setengah reaksi dalam menyetarakan reaksi reduksi oksidasi adalah 0,000 sampai 0,860 validitas rata-rata 0,426 yang menyatakan validitas cukup.

\section{Reabilitas}

Hasil analisis koefisien relabilitas test yang diuji cobakan harga r11 untuk cara perubahan bilangan oksidasi adalah 0,63 dan r11 untuk setengah reaksi adalah 0,402 yang berarti korelasi sedang.

\section{Derajat Kesukaran}

Hasil analisis diperoleh harga deraja kesukaran untuk cara perubahan bilangan oksidasi antara 0,00 sampai 0,60 rata0rata 0,50 dan derajat kesukaran untuk cara setengah reaksi adalah antara 0,00 sampai 0,50 ratarata 0,30 berarti derajat kesukaran sedang.

\section{Daya Beda}

Daya beda untuk cara perubahan bilangan oksidasi antara 0,00 sampai 0.80 daya beda rata-rata 0,51 bearti daya beda termasuk kategori baik dan untuk cara setengah reaksi antara 0,00 sampai 0,80 daya beda ratarata 0,39 menyatakan daya beda cukup.

\section{Hasil Penelitian Inti}

Sebelum pengujian hipotesis, terlebih dahulu diadakan uji normalitas sampel, apakah sampel berdistribusi normal atau tidak. Dengan menggunakan uji Lilliefors. Setelah uji normalitas, dilakukan uji homogenitas untuk mengetahui apakah sampel homogen ata tidak dengan menggunakan uji kesamaan variansi.

Hasil belajar yang diperoleh siswa dapat dilihat pada tabel sebagai berikut.

Tabel 1. Skor mentah hasil belajar siswa kelas XII MIPA

Cara perubahan bilangan oksidasi dan siswa kelas cara setengah reaksi

\begin{tabular}{|c|c|c|}
\hline Kelas & Hasil Belajar & Jumlah Siswa \\
\hline XII MIPA 1 & 788899101010 & 40 Siswa \\
Cara Perubahan & 101010111111 & \\
Bilangan Oksidasi & 121212121212 & \\
& 121212131313 & \\
& 131313131414 & \\
\hline XII MIPA 3 & 141415151515 & \\
Cara Setengah & 867778 & 43 Siswa \\
Reaksi & 9910101010 & \\
& 101011111111 & \\
& 121212121213 & \\
& 131313131313 & \\
& 141414151515 & \\
\hline & 15 & \\
\hline
\end{tabular}

Tabel 2. Skor terjabar hasil belajar siswa kelas XII MIPA

Cara perubahan bilangan oksidasi dan siswa kelas cara setengah reaksi

\begin{tabular}{|c|l|lllllll|l|}
\hline Kelas & \multicolumn{5}{|c|}{ Hasil Belajar } & Jumlah Siswa \\
\hline XII MIPA 1 & 2,5 & 3 & 3 & 3 & 4 & 4 & 40 Siswa \\
CARA & 5 & 5 & 5 & 5 & 5 & 5 & \\
PERUBAHAN & 6 & 6 & 6 & 7 & 7 & 7 & \\
BILANGAN & 7 & 7 & 7 & 7 & 7 & 7 & \\
OKSIDASI & 8 & 8 & 8 & 8 & 8 & 8 & \\
& 8 & 8 & 8 & 9 & 9 & 10 & \\
& 10 & 10 & 10 & 10 & \\
\hline XII MIPA 3 & 3 & 3 & 4 & 4 & 4 & 5 & 43 Siswa \\
CARA & 5 & 5 & 5 & 5 & 5,5 & 5,5 & \\
SETENGAH & 5,5 & 5,5 & 6 & 6 & 6 & 6 & \\
REAKSI & 6 & 6 & 7 & 7 & 7 & 7 & \\
& 8 & 8 & 8 & 8 & 8 & 8,5 & \\
& 8,5 & 8,5 & 8,5 & 8,5 & 8,5 & \\
& 8,5 & & & & \\
& 9 & 9 & 9 & 10 & 10 & 10 & \\
& 10 & & & & & \\
&
\end{tabular}

\section{Uji Normalitas}

Hasil uji normalitas menunjukkan nilai Lo1 untuk kelas cara perubahan bilangan oksidasi sama dengan 0,1026 dan Lo2 untuk kelas cara setengah reaksi sama dengan 0,1107. Hasil tersebut dikonsultasikan pada tabel nilai kritis uji Lilliefors dengan menggunakan tingkat kepercayaan $5 \%$ diperoleh harga $\mathrm{L}$ tabel sama dengan $0,886 / \sqrt{\mathrm{n}}$ untuk $\mathrm{n}>30$.

\section{Uji Homogenitas}

Hasil perhitungan uji homogenitas kedua kelompok sampel diperoleh harga Fo hitung sama dengan 0,664. Haga tersebut dikonsultasikan pada tabel $F$ yaitu 1,73 dengan taraf kepercayaan $5 \%$ Fo hitung $<F$ tabel berarti kedua sampel mempuyai variansi yang sama.

\section{Pembahasan}

Hasil belajar untuk aspek aplikasi dengan pengajaran cara perubahan bilangan oksidasi dan cara setengah reaksi memperlihatkan hasil rata-rata sama dengan 11,75 dan 10,8. Dari hasil rata-rata kedua pengajaran dapat diketahui bahwa pengajaran reaksi redoks dengan cara perubahan bilangan oksidasi lebih tanggi dari pada cara setengah reaksi. Perbedaan hasil belajar ini tidak signifikan pada taraf 0,05.

Kenyataan nilai rata-rata siswa yang diperoleh dapat dipahami karena kemungkinan besar siswa dalam menjawab dan menyelesaikan soal-soal test hasil belajar benar-benar sesuai dengan

Kenyataan nilai rata-rata siswa yang diperoleh dapat dipahami karena kemungkinan besar siswa dalam menjawab dan menyelesaikan soal-soal test hasil belajar benar-benar sesuai dengan kemampuan yng dimiliki. Beberapa hari sebelum test hasil belajar dilaksanakan, siswa telah diberitahuan cara penyetaraan reaksi reduksi oksidasi yang digunakan yaitu kelas XII MIPA 1 untuk 
Fauziah, Studi Perbandingan Pengajaran Reaksi Reduksi Oksidasi Antara Cara Perubahan Bilangan Oksidasi dengan Cara Setengah Reaksi terhadap Hasil Belajar Siswa Kelas XII IPA 1 dan XII IPA 2

cara perubahan bilangan oksidasi dan kelas XII MIPA 2 untu setengah reaksi.

Dalam mempelajari reaksi reduksi oksidasi telah dikembangkan suatu konsep yang terdiri atas angka yang bulat untuk dapat mengikuti pemindahan elektron. Angka ini disebut bilangan oksidasi atau tingkat oksidasi yang disusun berdasarkan suatu peninjauan tetang komposisi senyawa, keelektronegatifan relatif unsur dalam senyawa dan beberapa aturan menurut perjanjian (Anonim, 1979). Selanjutnya dijelaskan bahwa kedua cara penyetaraan reaksi redoks perl utuk memberikan bilangan oksidasi kepada tiap keadaan unsur yang muncul dalam peramaan (Keenan, dkk, 1986). Dengan demikian baik dengan cara perubahan bilangan oksidasi ataupun dengan cara setengah reaksi perlu diberikan bilangan oksidasi.

Bila diperhatikan langkah keempat penyetaraan reaksi rediks dengan cara perubahan bilangan oksidasi dan langkah ketiga penyetaraan reaksi redoks dengan cara setengah reaksi, dapat dijelaskan bahwa antara cara perubahan bilangan oksidasi dengan cara setengah reaksi sama-sama menggunakan elektron untuk enyeimbangkan persamaan reaksi-reaksi redoks, sedangkan langkah-langkah penyetaraan reaksi redoks yang lainnya adalah sama.

\section{SIMPULAN}

Kesimpulan yang diperoleh dari hasil penelitian yang telah dilaksanakan, sebagai berikut :

1. Nilai rata-rata hasil belajar yang dicapai siswa dengan pengajaran cara perubahan bilangan oksidasi dan cara setengah reaksi dalam menyetarakan persamaan reaksi redoks tergolong cukup baik, yaitu sebesar 11,75 dan 10,8

2. Pengajaran reaksi reduksi oksidasi antara cara perubahan bilangan oksidasi antara cara perubahan bilangan oksidasi dan cara setengah reaksi tidak menunjukkan perbedaan hasil belajar siswa kelas XII MIPA 1 dan XII MIPA 2.

\section{DAFTAR PUSTAKA}

Abdulhak, I., 1986, Strategi Belajar Pendidikan Luar Sekolah, Modul 4-6, Universitas Terbuka, Jakarta.

Anonim, 1979, Ilmu Kimia Untuk SMA, Balai Pustaka, Jakarta.

Arikunto, S., 1990, Prosedur Penelitian Suatu Pendekatan Praktik, Bina Aksara, Jakarta.

Keenan, Kleinfelter dan Wood, 1986, Kimia Untuk Universitas, Erlangga, Jakarta.

Idris. Z., 1987, Dasar-Dasar Kependidikan, Angkasa, Bandung.

Mappa, Achsin dan La Sulo, 1984, Teori Belajar Mengajar, PPLPTK, Dikti, Debdikbud, Jakarta.

Nasution, S., 1987, Berbagi Pendekatan dalam Proses Belajar dan Mengajar, Bina Aksara, Jakarta.
Nurkancana, W. Dan PPN. Sumartana, 1986, EvaluasiPendidikan, Usaha Nasional, Surabaya.

Polling, C. Dan Tjokrodanoerdjo, R.H., 1989, Ilmu Kimia SMA, Erlangga, Jakarta.

Ronowisroyo, S., 1980, Peranan Gedung Sekolah dan Perabotannya Terhadap Mutu Pendidikan, Analisis Pendidikan Tahun 1 Nomor 2, Depdikbud, Jakarta.

Subiona, 1987, Konstruksi dan Analisis Test Suatu Pengantar Pada Teori Test dan Pengukuran, PPLPTL., Dikti Depdikbud, Jakarta. 